\title{
Mobile phone use among commercial drivers in Ghana: An important threat to road safety
}

\author{
Isaac Donkor ${ }^{1}$, Adam Gyedu², Anthony K. Edusei ${ }^{3}$, Beth E. Ebel ${ }^{4}$ and Peter Donkor ${ }^{2}$ \\ Ghana Med J 2018; 52(3): 122-126 doi: http://dx.doi.org/10.4314/gmj.v52i3.3
}

\author{
${ }^{1}$ Ghana Red Cross Health Services, Brong Ahafo Region, Sunyani, Ghana \\ ${ }^{2}$ Department of Surgery, School of Medical Sciences, KNUST, Kumasi, Ghana \\ ${ }^{3}$ School of Public Health, KNUST, Kumasi, Ghana \\ ${ }^{4}$ Departments of Pediatrics and Epidemiology, University of Washington, Seattle, WA, USA; and Harborview Injury \\ Prevention \& Research Center, Seattle, WA. USA
}

Corresponding author: Dr. Adam Gyedu

E-mail: drgyedu@gmail.com

Conflict of interest: None declared

\begin{abstract}
SUMMARY
Background: Ghana passed a law in 2012 banning the use of mobile phones while driving. However, data on compliance to the law has been lacking.

Objective: To examine factors associated with mobile phone use while driving among Ghanaian commercial drivers.

Methods: A survey was conducted among 627 commercial drivers (98.0\% response rate). Bivariate and multivariate logistic regressions were performed to determine how a priori covariates influenced commercial drivers' use of phones while driving. The covariates included driver age, education, driving route distance, driving under the influence (DUI), and knowledge that phone use during driving causes distraction.

Results: Respondents were aware of the law (94.7\%) but compliance was low (38\%). Drivers who did not believe that cell phone use contributed to crash risk were more likely to report distracted driving (AOR 2.02,95\%CI 1.053.9). Drivers who had completed primary (AOR 4.49,95\%CI 1.14-17.78) or at least senior high school (AOR 6.89,95\%CI 1.5-31.59) had increased odds of using the phone while driving, compared to those having no formal education. Drivers with 6-10 years (AOR 2.00,95\%CI 1.00-3.98) or >10 years driving experience (AOR 2.87,95\%CI 1.24-6.62) were more likely to report distracted driving compared to those with $\leq 5$ years' experience. Drivers who travelled longer distances were more likely to report distracted driving (AOR 2.41,95\%CI 1.23-4.71). Those who had never engaged in DUI were less likely to use the phone while driving (AOR 0.06,95\%CI 0.01-0.43).

Conclusion: Future prevention efforts for distracted driving in Ghana will require targeted distracted driving enforcement and education for commercial drivers and their passengers.
\end{abstract}

Funding: This study was funded, in part, by a grant (D43-TW007267) from the Fogarty International Center, US National Institutes of Health. The content is solely the responsibility of the authors and does not necessarily represent the official views of the National Institutes of Health.

Keywords: Mobile phone, commercial drivers, Ghana, road safety, distracted driving

\section{INTRODUCTION}

Road traffic injuries contribute to 1.25 million deaths worldwide annually, with $90 \%$ occurring in low- and middle-income countries (LMICs). ${ }^{1,3}$ In Ghana, road traffic crashes cause an average of 6 deaths daily.,5 Poor traffic infrastructure, limited investment in pedestrian safety, inadequate road maintenance, high vehicle speeds, and impaired driving have been identified among factors that influence road traffic crashes and the injuries they cause.,
The growing use of mobile phones in everyday life has resulted in increased cell phone use among drivers. The World Health Organization in 2011, reported an 11\% prevalence of mobile phone use while driving. ${ }^{8}$ Phone use distracts the driver, delaying reaction to traffic signals, increasing lapse in decision making and reducing awareness of other vehicles and pedestrians. ${ }^{9}$ Ghana passed a law, Road Traffic Regulations, 2012 (L.I 2180), in 2012 banning the use of mobile phones while driving. ${ }^{10}$ 
However, data on phone use while driving is lacking. We aimed to identify the proportion of Ghanaian commercial drivers who use phones while driving and examined factors associated with their reported use. ${ }^{10 .}$ Through this work, we plan to highlight target areas for an intervention to reduce distracted driving in Ghana.

\section{METHODS}

\section{Setting}

Kumasi is the second largest city in Ghana, with a population of 1.7 million. We conducted a survey of commercial drivers at Kejetia, the largest lorry station in Kumasi. There were 19 registered driver unions operating in the station with around 1,000 vehicles that serve over 30,000 passengers daily. Lorry routes range from short intercity trips to longer trips to neighboring countries.

\section{Sampling and Data Collection}

We conducted a cross-sectional survey of commercial drivers, all of whom use mobile phones. In 2015, over $80 \%$ of the Ghanaian population owned a mobile phone. ${ }^{11}$ Assuming this as the prevalence of mobile phone use among commercial drivers, we estimated a sample size of 640 drivers for the survey, using the Cochran Sample Size Estimation Equation. ${ }^{12}$

The 19 recognized driver unions at the Kejetia lorry station were assigned random numbers with the help of a random number generator. The generated numbers were then listed in order of ascending magnitude and unions corresponding to the first 10 numbers were selected.

From within each union, a convenience sample of 64 drivers was selected as the unions had comparable memberships. No incentive was provided for participation. A two-page oral questionnaire was developed to assess commercial drivers' viewpoints and practices on mobile phone use while driving. The survey was conducted by research assistants who underwent training that emphasized techniques such as managing interview environment, active listening, open questioning and probing techniques.

The survey was conducted in Ashanti Twi and backtranslated into English to ensure validity of verbal translation. Verbal consent was obtained from all drivers before the interviews. All data were collected anonymously with data extraction sheets and entered in Excel (Microsoft Corp., USA) for data cleaning.

\section{Data Analysis}

Data were analyzed using STATA v14 (StataCorp, USA) and expressed with descriptive statistics. Bivariate and multivariate logistic regression was performed to determine the factors that influence commercial driver report of cell phone use while driving.

The multivariate model included a priori covariates considered to contribute to the outcome (e.g., driver age, educational background, and distance of driving route, driving under the influence (DUI), and knowledge that phone use during driving causes distraction).

\section{Ethics}

The study was approved by The Kwame Nkrumah University of Science and Technology Committee for Human Research and Publication Ethics (Reference number: CHRPE/AP/204/15). It was also reviewed by University of Washington Human Subjects Division and found to be exempt (Document number: 1207; Version \# 3.0-03/27/2015).

\section{RESULTS}

\section{Demographics and Driving Characteristics}

We approached 640 drivers; $98.0 \%$ agreed to participate in the anonymous survey. The median age of drivers was 36 years. All drivers surveyed were males. Most drivers had completed primary school education (6 years) (77.4\%). The median driving experience was 15 years; over one-third had over 10 years of driving experience. Almost all the drivers owned a license fit for the type of vehicle they drove.

The majority learned commercial driving skills as a driver's mate/assistant. Sixty-one percent drove larger lorries with capacity to seat 18 or more and the majority $(87.9 \%)$ reported they had never driven under the influence of alcohol or drugs (Table 1).

\section{Phone Use While Driving}

The majority of drivers (96.4\%) stated that they were aware of the law banning phone use while driving. However, 59.6\% did not routinely comply with the law. Among drivers who reported phone use while driving, $44.6 \%$ stated they used the hands-free feature.

Drivers reported that the majority of phone use was to communicate with colleague drivers about events on the road, though this could not be independently verified. Over one-quarter of the respondents did not believe that phone use caused a distraction while driving. 
Table 1 Demographic and characteristics of commercial drivers in Kumasi, Ghana ( $\mathrm{N}=627)$

\begin{tabular}{|c|c|c|}
\hline Item & $\mathbf{n}$ & $\%$ \\
\hline Age, median (IQR) years & $36(19-65)$ & \\
\hline Driving experience, median (range), years & $15(1-45)$ & \\
\hline $\begin{array}{l}\text { Duration of work per day, median } \\
\text { (range), hours }\end{array}$ & $6(1-19)$ & \\
\hline \multicolumn{3}{|l|}{ Education status } \\
\hline None & 21 & 3.3 \\
\hline Primary & 485 & 77.4 \\
\hline Senior high & 104 & 16.6 \\
\hline Tertiary & 4 & 0.6 \\
\hline Missing & 13 & 2.1 \\
\hline \multicolumn{3}{|l|}{ Working experience at lorry station } \\
\hline$\leq 5$ years & 203 & 32.4 \\
\hline 6 - 10 years & 186 & 29.7 \\
\hline$>10$ years & 234 & 37.3 \\
\hline Missing & 4 & 0.6 \\
\hline \multicolumn{3}{|c|}{ Licensed to drive the vehicle they currently drive } \\
\hline No & 11 & 1.8 \\
\hline Yes & 616 & 98.2 \\
\hline \multicolumn{3}{|l|}{ Method of training } \\
\hline Driving school & 44 & 7.0 \\
\hline On-the-job training & 436 & 69.5 \\
\hline Taught by friend & 111 & 17.7 \\
\hline Others & 33 & 5.3 \\
\hline Missing & 3 & 0.5 \\
\hline \multicolumn{3}{|l|}{ Vehicle type } \\
\hline Taxi & 7 & 1.1 \\
\hline Small van ( $\leq 17$ seating capacity) & 215 & 34.3 \\
\hline Large van (18 - 24 seating capacity) & 384 & 61.2 \\
\hline Bus (25 - 32 seating capacity) & 10 & 1.6 \\
\hline Missing & 13 & 2.1 \\
\hline \multicolumn{3}{|l|}{ Driving route } \\
\hline Short distance (within region) & 485 & 77.4 \\
\hline Long distance (outside region) & 139 & 22.1 \\
\hline Missing & 3 & 0.5 \\
\hline \multicolumn{3}{|c|}{ Ever driven under the influence of alcohol or drugs } \\
\hline No & 551 & 87.9 \\
\hline Yes & 73 & 11.6 \\
\hline Missing & 3 & 0.5 \\
\hline
\end{tabular}

Among drivers who reported that they used a cell phone while driving, $2.5 \%$ had been involved in a crash while using the phone, and $12.4 \%$ reported a near-crash event while using the phone (Table 2).

Factors associated with phone use while driving In the multivariate model, reported cell phone use while driving was positively associated with a higher educational background, more driving experience, and a longer driving route distance (Table 3).

Our study found that drivers who believed cell phones did not contribute to crash risk were twice as likely to report distracted driving compared to drivers who were aware of the risks (AOR 2.02, 95\%CI 1.05-3.9).

Distracted driving was also reported more commonly among drivers with a history of having driven under influence and those who did not believe that phone use while driving caused distraction.

Table 2 Phone use while driving among commercial drivers in Kumasi, Ghana

n $\%$

\begin{tabular}{|c|c|c|}
\hline \multicolumn{3}{|c|}{ Knowledge of law banning mobile phone use while driving $(\mathrm{N}=616)$} \\
\hline No & 22 & 3.6 \\
\hline Yes & 594 & 96.4 \\
\hline \multicolumn{3}{|c|}{ Ever used the phone while driving $(\mathrm{N}=594)$} \\
\hline No & 240 & 40.4 \\
\hline Yes & 354 & 59.6 \\
\hline \multicolumn{3}{|c|}{ Function of phone used while driving $(\mathrm{N}=342)$} \\
\hline Making / Receiving calls & 339 & 99.1 \\
\hline Texting & 0 & 0 \\
\hline Browsing the internet & 3 & 0.9 \\
\hline \multicolumn{3}{|c|}{ Reason for phone use while driving $(\mathrm{N}=329)$} \\
\hline Coworkers & 263 & 79.9 \\
\hline Communicating with Family & 16 & 4.9 \\
\hline Communicating with customers & 50 & 15.2 \\
\hline \multicolumn{3}{|c|}{ Does mobile phone use distract you while driving? $(\mathrm{N}=429)$} \\
\hline No & 117 & 27.3 \\
\hline Yes & 312 & 72.7 \\
\hline \multicolumn{3}{|c|}{ Aware of risks of mobile phone use while driving? $(\mathrm{N}=585)$} \\
\hline No & 48 & 8.5 \\
\hline Yes & 537 & 91.5 \\
\hline \multicolumn{3}{|c|}{ Ever driven above state posted speed limit $(\mathrm{N}=612)$} \\
\hline No & 395 & 64.5 \\
\hline Yes & 217 & 35.5 \\
\hline \multicolumn{3}{|c|}{ Involved in car crash while using a mobile phone $(\mathrm{N}=354)$} \\
\hline No & 345 & 97.5 \\
\hline Yes & 9 & 2.5 \\
\hline \multicolumn{3}{|c|}{ Involved in near car crash while using a mobile phone $(\mathrm{N}=354)$} \\
\hline No & 310 & 87.6 \\
\hline Yes & 44 & 12.4 \\
\hline
\end{tabular}

Compared to having no formal education, having completed primary (AOR 4.49, 95\%CI 1.14-17.78) or at least a senior high school education (AOR 6.89, 95\%CI 1.5-31.59) increased a driver's odds of using the phone while driving.

Commercial drivers with 6-10 years (AOR 2.00, 95\%CI 1.00-3.98) or more than 10 years driving experience (AOR 2.87, 95\%CI 1.24-6.62) had higher odds of using a phone while driving compared to those with five years or less experience.

Drivers who travelled longer distances (AOR 2.41, 95\%CI 1.23-4.71) and those who did not believe that phone use caused distraction while driving (AOR 2.02, 95\%CI 1.05-3.9) were more likely to engage in phone use while driving. Those who had never driven under the influence were much less likely to use the phone while driving (AOR 0.06, 95\%CI 0.01-0.43). 
Table 3 Factors associated with mobile phone use while driving among commercial drivers in Kumasi, Ghana

\begin{tabular}{|c|c|c|}
\hline Variable & AOR & $95 \% \mathrm{CI}$ \\
\hline Age & 0.99 & $0.96-1.03$ \\
\hline \multicolumn{3}{|l|}{ Educational background } \\
\hline No education & Referent & \\
\hline Primary & 4.49 & $1.14-17.78$ \\
\hline SHS and above & 6.89 & $1.5-31.59$ \\
\hline \multicolumn{3}{|l|}{ Driving experience } \\
\hline$\leq 5$ years & Referent & \\
\hline $6-10$ years & 2.0 & $1.0-3.98$ \\
\hline$>10$ years & 2.87 & $1.24-6.62$ \\
\hline \multicolumn{3}{|l|}{ Driving route } \\
\hline $\begin{array}{l}\text { Short distance (within re- } \\
\text { gion) }\end{array}$ & Referent & \\
\hline $\begin{array}{l}\text { Long distance (outside re- } \\
\text { gion) }\end{array}$ & 2.41 & $1.23-4.71$ \\
\hline Yes & Referent & \\
\hline No & 0.57 & $0.01-0.43$ \\
\hline Yes & Referent & \\
\hline No & 2.02 & $1.05-3.9$ \\
\hline
\end{tabular}

\section{DISCUSSION}

This study found that most commercial drivers at the Kumasi Kejetia lorry station were aware of the law banning phone use while driving in Ghana. However, relatively few drivers (40\%) complied with the law. Among drivers who admitted to cell phone use while driving, $14.9 \%$ had been involved in a crash or near-crash event while using their phones on the road. Having a formal education, more driving experience, being a longer distance driver and believing that phone use did not distract from the task of driving increased drivers' odds of using the phone while driving. Drivers who reported they had never driven while impaired had reduced odds of using the phone while driving. Drivers stated that they most commonly used the phone while driving to communicate about events on the road.

Drivers with more driving experience were more likely to use a phone while driving. It is possible that these drivers become overconfident with driving experience or have less education on the risks of distracted driving. Drivers with more than five years' experience (regardless of age) were more likely to engage in risky driving practices like phone use while driving. ${ }^{13}$

Drivers who stated they were unaware of the distraction caused by phone use were twice more likely to use a cell phone while driving. There has not been unanimous agreement with this apparently logical finding; while there are studies supporting our finding. ${ }^{14,15}$ one report concluded that awareness of the risks posed by phone use does not influence its use while driving. ${ }^{16}$

Having formal education was associated with increased odds of a driver engaging in phone use while driving.
Higher educational level exposes drivers to the familiarity of phone use in general and may also be associated with higher incomes which enable cell phone use. ${ }^{16}$ It is unsurprising that drivers who do not engage in DUI were less likely to use a phone while driving. Drivers who complied with one safe driving law, such as not engaging in DUI, reported improved compliance with another safe driving law, such as refraining from phone use while driving. ${ }^{18,19}$

Forty-five percent of drivers who used the phone while driving did so with the hands-free feature, although the practice is also not permitted under Ghanaian law. The use of hands-free while driving has been made obligatory in many countries. ${ }^{19}$ However, hands-free use still has the risk of cognitive distraction, and may offer only limited safety advantage over hand-held phone regarding road traffic crashes. ${ }^{8,19}$ It might even tempt drivers to use the phone more while driving by inducing a false sense of security. As the proportion of phone users increases in LMICs, it is imperative to change drivers' perception about hands-free use in order to avoid the distraction it causes during driving. ${ }^{13,21,22}$

The study was limited by the survey capturing only selfreported behaviors. We were not able to directly observe distracted driving, nor were we able to examine crash or collision rates for drivers. Drivers may have felt pressure to provide socially acceptable answers; however social desirability bias may have been somewhat allayed in this anonymous study which did not collect any individual identifying information.

\section{CONCLUSION}

Although most commercial drivers at the Kumasi Kejetia lorry station know about the law banning phone use while driving, compliance rate remains low. Our study found that drivers who did not believe that cell phone use contributed to crash risk were twice as likely to report distracted driving compared to drivers who were aware of the risks.

Our study identified opportunities to improve education about Ghanaian laws prohibiting distracted driving for all drivers, including commercial drivers who may put many passengers and pedestrians at risk. International studies on distracted driving also suggest that education alone is unlikely to change behavior unless accompanied by enforcement efforts, as most drivers believe they are "safe" from crash, but feel at risk of a citation. Further studies involving observed cell phone use while driving and linkage to crash and citation rates are also needed to verify our findings.

\section{ACKNOWLEDGEMENT}


We wish to express our sincere thanks to Prof. Charles Mock for his advice and support and to the commercial drivers who participated in the study.

\section{REFERENCES}

1. Al Reesi H, Al Maniri A, Plankermann K, Al Hinai M, Al Adawi S, Davey J, et al. Risky driving behavior among university students and staff in the Sultanate of Oman. Accident Analysis \& Prevention 2013;58:1-9.

2. World Health Organization. Global status report on road safety. Geneva, Switzerland: WHO; 2015.

3. Stewart BT, Quansah R, Gyedu A, Boakye G, Abantanga F, Ankomah J, et al. Serial Assessment of Trauma Care Capacity in Ghana in 2004 and 2014. JAMA Surg 2016;151(2):164-71.

4. Salifu M, Ackaah W. Under-reporting of road traffic crash data in Ghana. Int J Inj Contr Saf Promot 2012;19(4):331-9.

5. Afukaar FK, Agyemang W, Most I. Accident statistics 2007. Kumasi, Ghana: Building and Road Research Institute; Council for Scientific and Industrial Research; 2008.

6. Bjerre J, Kirkebjerg PG, Larsen L. Prevention of traffic deaths in accidents involving motor vehicles. Ugeskrift for Laeger 2006;168(18):1764-8.

7. Forson PK, Gardner A, Oduro G, Bonney J, Biney EA, Oppong C, et al. Frequency of Alcohol Use Among Injured Adult Patients Presenting to a Ghanaian Emergency Department. Annals of Emergency Medicine 2016;68(4):492-500.

8. World Health Organization. Mobile phone use: a growing problem of driver distraction. Geneva, Switzerland: World Health Organization; 2011.

9. Dragutinovic N, Twisk D. Use of mobile phones while driving-effects on road safety. Leidschendam, The Netherlands: SWOV Institute for Road Safety Research; 2004.

10. Partners for Safe Driving Ghana. New provisions in the road traffic regulations, 2012 L.I.2180 [July 18, 2018]. Available from: https://partnersforsafedriving.wordpress.com/lawand-order/new-provisions-in-the-road-trafficregulations-2012-l-i-2180/.

11. Pew Research Center. Cell Phones in Africa: Communication Lifeline 2015 [Available from: http://www.pewglobal.org/2015/04/15/cell-phonesin-africa-communication-lifeline/.
12. Sample Size in Statistics [1 March 2018]. Available from: http://www.statisticshowto.com/probabilityand-statistics/find-sample-size/.

13. Knipling RR, Truck C, Program BSS, Administration USFMCS. Individual Differences and the "high-risk" Commercial Driver: Transportation Research Board; 2004.

14. McEvoy SP, Stevenson MR, Woodward M. Phone use and crashes while driving: A representative survey of drivers in two Australian states. The Medical Journal of Australia 2006;185(11-12):630-4.

15. Chumpawadee U, Homchampa P, Thongkrajai P, Suwanimitr A, Chadbunchachai W. Factors related to motorcycle accident risk behavior among university students in northeastern Thailand. The Southeast Asian $J$ Trop Med Public Health 2015;46(4):805-21.

16. McEvoy SP, Stevenson MR, Woodward M. The impact of driver distraction on road safety: results from a representative survey in two Australian states. Inj Prev. 2006;12(4):242-7.

17. Shi J, Xiao Y, Atchley P. Analysis of factors affecting drivers' choice to engage with a mobile phone while driving in Beijing. Transportation Research part F: Traffic Psychology and Behaviour 2016;37:1-9.

18. Sun D, Jia A. Impacts of cell phone use on driving safety and drivers' perception of risk. Journal of Modern Transportation 2016;24(2):145-52.

19. Bener A, Atan F, Bolat E, Yildirim E, Crundall D. Misuse of mobile phone conversation while driving: Driver distraction a major public health problem. The Nigerian Journal of General Practice. 2016;14(2):17-22.

20. Pöysti L, Rajalin S, Summala H. Factors influencing the use of cellular (mobile) phone during driving and hazards while using it. Accident Analysis \& Prevention 2005;37(1):47-51.

21. Drury C, Abussaud Z, Allison G, Bhindi E, Bustard J, Chamberlain J, et al. Mobile Phone Use While Driving After a New Law: Observational Study. Wellington, New Zealand: University of Otago; 2012.

22. Horrey WJ, Wickens CD. Examining the impact of cell phone conversations on driving using metaanalytic techniques. Human Factors 2006; 48(1):196-205 